International Journal of Engineering \& Technology, $7(2.12)(2018)$ 338-343
International Journal of Engineering \& Technology
SPC
Website: www.sciencepubco.com/index.php/IJET
Research Paper

\title{
A Practical performance verification of AFLC based MPPT for standalone PV power system under varying weather condi-tion
}

\author{
Neeraj Priyadarshi ${ }^{1}$, Amarjeet Kr. Sharma ${ }^{1}$, Akash Kumar Bhoi ${ }^{2}$, \\ S.N. Ahmad ${ }^{1}$, Farooque Azam ${ }^{1}$, S. Priyam ${ }^{1}$ \\ ${ }^{1}$ Millia Institute of Technology, Purnea 854301, India \\ ${ }^{2}$ Dept. of Electrical and Electronics Engineering, Sikkim Manipal Institute of Technology, SMU, Sikkim, INDIA-737136 \\ *Corresponding author E-mail: neerajrjd@gmail.com
}

\begin{abstract}
For amelioration of tracking efficiency, the Maximum power point trackers (MPPT) are very important for photovoltaic (PV) generation. For this purpose here a reformed adaptive fuzzy logic control (FLC) MPPT tracker has been presented to enhance its overall power efficiency and gives rapid transient response under changing weather conditions. For voltage regulation at load bus, the zeta buck-boost converter has been taken for its least voltage ripple. MATLAB/SIMULINK simulation environment and dSPACE DS1104 real time control board is used to test the proposed adaptive fuzzy logic controller based MPPT in variable irradiance level and ambient temperature. The tracking efficiency in this presented method is analyzed in comparison with standard fuzzy logic controller (FLC) and perturb and observe (P and O) MPPT algorithms. The modified AFLC controller gives better tracking efficiency and precise response compared to conventional fuzzy logic controller and P and O MPPT algorithms. Theoretical and experimental results obtained are demonstrated for improved functioning of the system.
\end{abstract}

Keywords: AFLC; FLC; MPPT; Perturb Observe (P and O); Zeta Buck-Boost Converter.

\section{Introduction}

Due to large scale depletion of conventional fossil fuels, the clean, green and eco-friendly renewable energy sources have considered the more attention to the researchers. There are many renewable energy sources like wind, fuel cells, geothermal, solar energy etc. The PV system is taken as a most promising renewable energy technology among the other renewable source because of pollution free, low maintenance cost and easily availability. [1-3]. However, the energy conversion rate of present PV system is very low.The efficient solution to increase the photovoltaic energy conversion efficiency is application of MPPT trackers. While designing the MPPT method, irradiance level and temperature are the controlling factors, which kept in consideration since the power generation from the PV system depends on these two factors. During all atmospheric conditions, the major objective of MPPT is to locate the global position near to maximum power point (MPP).[4-8]. For maximum extraction of PV power, there are various MPPT algorithms have been used. Some of the maximum powers tracking algorithms are discussed in this literature such as incremental conductance, $\mathrm{P}$ and $\mathrm{O}$ method, fuzzy logic controller algorithms, etc. [9-12]. The main drawback of the incremental conductance method is oscillation around MPP and could be failed to track the MPP in the reverse orientation due to adverse operating situations. $\mathrm{P}$ and $\mathrm{O}$ is the other MPPT method used for maximum extraction of powers from the PV panel. Using this algorithm, the solar panel output voltage is periodically modified and the resulting output power is analyzed comparing with the preceding output power. Fuzzy logic controller based MPPT have been used due to fast tracking under rapid ambient conditions. It is uncomplicated and does not demand mathematical model and has low cost [13-14]. Hence, to achieve the better tracking efficiency of the PV system, here modified AFLC based MPPT is presented. However in case of varying operating conditions in a large range and unreliable expert knowledge, the conventional fuzzy logic controller with fixed parameters is not suitable in application. The proposed AFLC is the appropriate solution to this problem to get better performance as it can readjust the fuzzy parameters. The AFLC based MPPT controller has been practically interfaced with dSPACE platform. Such PV system structure with dSPACE 1104 platform have neither implemented nor discussed before by author's best knowledge.

\section{PV system description}

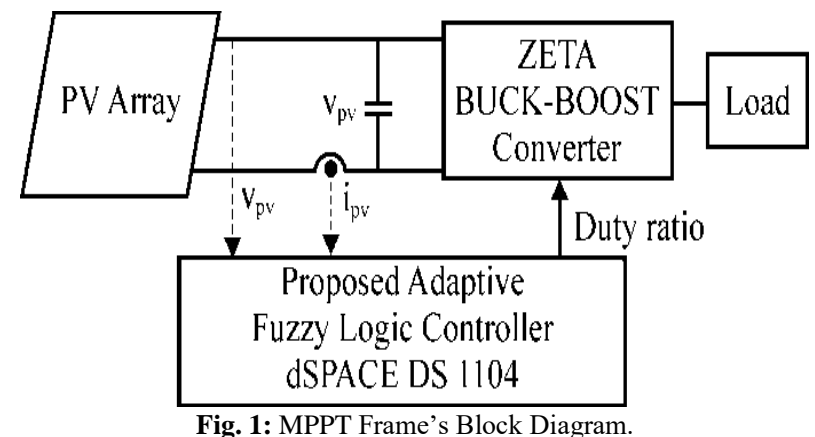

Fig. 1: MPPT Frame's Block Diagram. 
Fig. 1 depicts the MPPT frame block diagram of the presented photovoltaic system. Here, a dSPACE interface is used to implement the AFLC which generates the gating pulses for power switch of zeta buck-boost converter. It consists of main three constituents: (i) PV array (ii) zeta buck-boost (iii) AFLC MPPT tracker.

\subsection{PV array characteristics}

Fig 2(a) and 2(b) depict the I-V and P-V PV module curve using MATLAB/simulink tool under different operating condition such as variable ambient temperature and sun insolation.

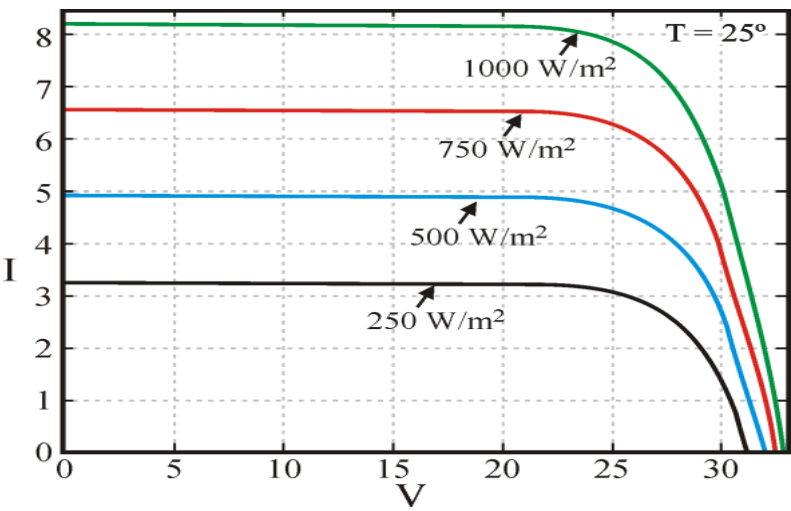

Fig .2: (A) PV Module I-V Simulated Curve With Varying Sun Insolation And Steady Temperature.



Fig .2: (B) PV Module P-V Simulated Curve With Varying Sun Insolation And Steady Temperature.

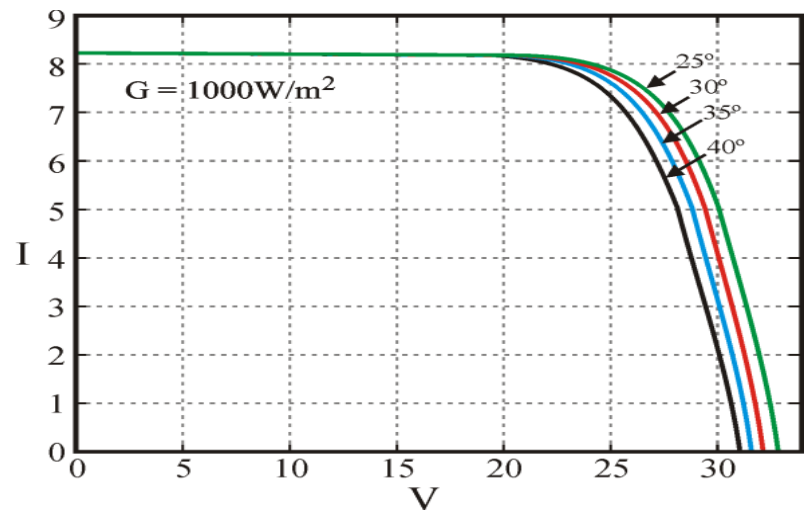

Fig. 3: (A) PV Module I-V Simulated Curve With Varying Temperature And Steady Sun Insolation.



Fig. 3: (B): PV Module P-V Simulated Curve with Varying Temperature and Steady Sun Insolation.

Fig. 3 presents simulated I-V and P-V responses, when external temperature is varying and irradiance level is maintained constant at $1000 \mathrm{~W} / \mathrm{m}^{2}$. Moreover the $\mathrm{I}-\mathrm{V}$ and $\mathrm{P}-\mathrm{V}$ curves at constant sun insolation with variable temperature are depicted by 3(a) and (b), respectively.

\subsection{Zeta buck-boost converter}

The MPPT action can be performed by employing buck-boost behavior of zeta converter. It mainly provides low output ripple with MPPT action. It comprises two inductors and capacitor which are responsible for amplification and reduction of supply voltage irrespective of inversion of polarities.

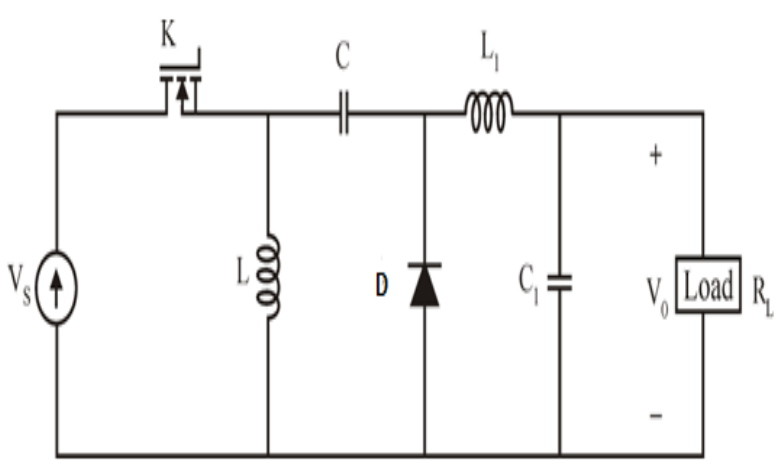

Fig. 4: Zeta Converter.

It works in two modes of operation which is explained in Fig.4. Electricity flows through inductor $\mathrm{L}_{1}$ and $\mathrm{L}_{2}$ with reverse biasing of diode when switch $\mathrm{K}$ is kept $\mathrm{ON}$. On the other hand, the $\mathrm{L}_{1}$ inductor has been discharged by $\mathrm{R}_{\mathrm{L}}$ resistor when switch $\mathrm{K}$ is kept off.

\subsection{Proposed adaptive fuzzy logic controller based MPPT}

Because of non-linear V-I nature of PV cell the MPPT tracker are employed to acquire peak power under varying climate too loading condition. Here AFLC based MPPT controller has been proposed to get high power occurs with respect to classical FLC control. The conventional FLC is not reliable when expert knowledge is insufficient and operating conditions are varied in large range. Hence, AFLC is presented which makes the controller independent of the expert knowledge and gives rapid transient response by adapting the fuzzy parameters. Adaptive fuzzy logic controller consists of two parts: (A) FLC control (B) Adaptive learning method Fig. 5 portrays block diagram of AFLC. 


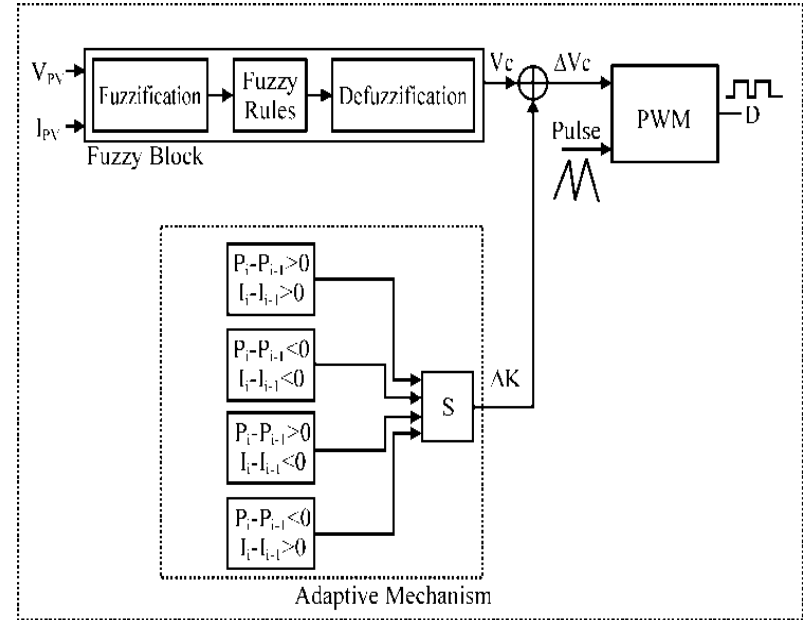

Fig. 5: Adaptive Fuzzy Logic Controller Russification, Ifference Engine And Defuzzification Are The Three Major Parts Constituting The FLC.

i). Fuzzification: It is a method in which the crisp values are Can be transformed to fuzzy parameters for this purpose the membership functions have been employed for input and output variables mathematically $\mathrm{V}_{\mathrm{pv}}(\mathrm{n})$ and $\mathrm{I}_{\mathrm{pv}}(\mathrm{n})$ has been derived as:

$V_{P V}(\mathrm{n})=\left[V_{P V}(n-1)+V_{P V}(n-2)\right] / 2$

$I_{P V}(\mathrm{n})=\left[I_{P V}(n-1)+I_{P V}(n-2)\right] / 2$

Where $\mathrm{V}_{\mathrm{pv}}(\mathrm{n})$ and $\mathrm{I}_{\mathrm{pv}}(\mathrm{n})$ are present PV voltage and current respectively: The optimal duty

ratio has been generated which is sent to power switch of zeta converter.



(a)

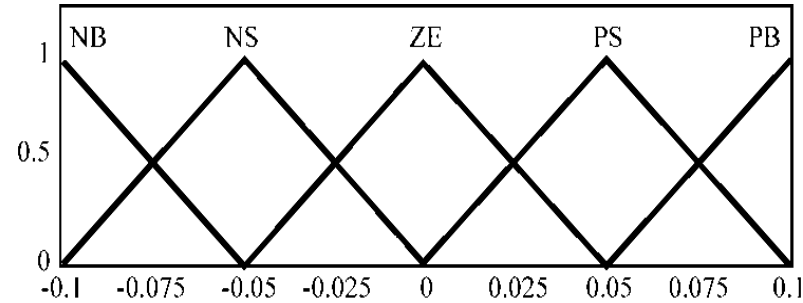

(b)

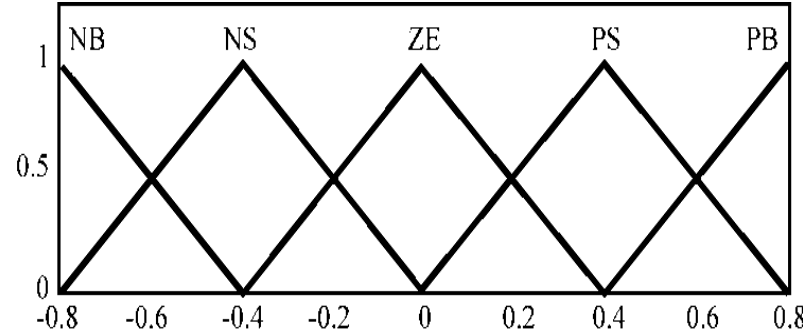

(c)

Fig. 6: Membership Function $I_{P V}(N)$ (B) Membership Function $V_{P V}(N)$ (C) Membership Function Duty Ratio.
This output is further utilized in giving switching pulses to zeta converter for proper operation of PV array. Fig. 6 illustrates the five specific linguistic variables (NB, NS, ZE, PS and PB) assigned for the input and output variables.

ii). Fuzzy Inference engine (Fuzzy rule base): To check the overall behaviour of PV system, the fuzzy rules are proposed to make fuzzy decisions. The rule base is based on max-min composition which is explained by Mamdani's method. Generated inference rules for the adaptive fuzzy system have been depicted by TABLE 1 .

Table 1: inference Rules for Aflc

\begin{tabular}{llllll}
\hline$I_{P V} V_{P V}$ & NB & NS & ZE & PS & PB \\
\hline NB & ZE & PS & NS & NB & PB \\
NS & PB & NS & PB & ZE & NS \\
ZE & PS & PS & NB & PS & NB \\
PS & NS & ZE & ZE & NS & ZE \\
PB & NS & PB & PB & ZE & PS \\
\hline
\end{tabular}

iii). Defuzzification: Using this method numerical value is obtained to control the fuzzy output. It converts the linguistic variables to numerical value to control the switch of power converter. This method uses centroid method to get duty ratio of Zeta converter. The generated reference PWM signal is sent to the switch of Zeta converter.

\subsection{Adaptive learning mechanism}

In order to obtain better response and maximum tracking PV output power, the duty ratio has been modified using adaptive mechanism. It consists of three parts: (i) The PPV (n) and Ipv (n) can be calculated by average of the previous value as equations (1) and (2). (ii) A comparison of the $P_{P V}(n)$ and $I_{P V}(n)$ with the previous value is performed. The differences can be positive or negative. Based on the differences, there are 4 set of rules (S) are shown in Table 2 .

Table 2: adaptive Mechanism Of Aflc

\begin{tabular}{lllll}
\hline \multirow{2}{*}{ Rule } & {$\left[\mathrm{P}_{\mathrm{PV}}(\mathrm{n})-\right.$} & {$\left[\mathrm{I}_{\mathrm{PV}}(\mathrm{n})-\mathrm{I}_{\mathrm{PV}}(\mathrm{n}-\right.$} & \multirow{2}{*}{ Duty Ratio } & Adaptive \\
& $\mathrm{P}_{\mathrm{PV}}(\mathrm{n}-1]>0$ & $1]>0$ & Value $\square \mathrm{K}$ \\
\hline$(1)$ & $\mathrm{T}$ & $\mathrm{T}$ & decrease a & \multirow{2}{*}{$\mathrm{K}_{\mathrm{A}}$} \\
$(2)$ & $\mathrm{F}$ & $\mathrm{F}$ & little & \\
$(3)$ & $\mathrm{T}$ & $\mathrm{F}$ & decrease a & $\mathrm{K}_{\mathrm{B}}$ \\
$(4)$ & $\mathrm{F}$ & $\mathrm{T}$ & lot & \\
\hline
\end{tabular}

i). Rules 1 and 2: The duty ratio is modified using rules 1 and 2 and the value of $\square \mathrm{K}$ is assumed as $\mathrm{KA}=-0.25$, since duty ratio can decreased a little.

ii). Rules 3 and 4: The duty ratio is modified using rules 3 and 4 and the value of $\square \mathrm{K}$ is assumed as $\mathrm{KB}=-0.6$, since duty ratio can decreased a lot

iii). Mathematically, duty ratio control voltage ( $\square \mathrm{VC})$ is defined as

$\Delta V_{c}=\mathrm{V}_{\mathrm{c}}+\Delta K$

Where $\mathrm{VC}=$ Output from defuzzification and $\mathrm{K}=$ Adaptive Value 


\section{Simulation results}


(a)
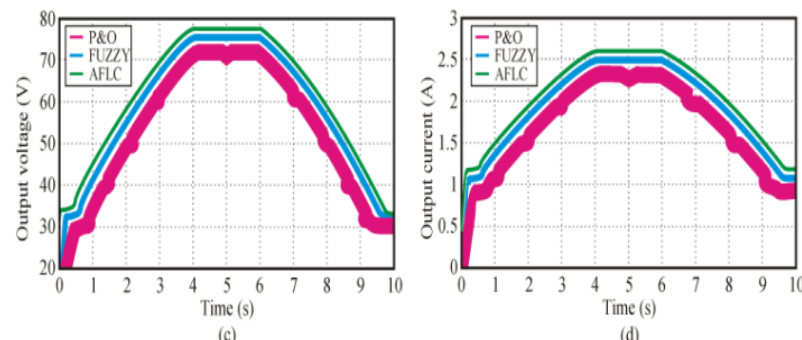

Fig. 7: Comparison Of AFLC, FLC And P\&O Method Under Varying Insolation And Steady Temperature (A) Variable Irradiance (B) Output Power (C) Output Voltage (D) Output Current.

The zeta buck-boost converter based on proposed adaptive Fuzzy logic MPPT is theoretically formulated through MATLAB/Simulink. The irradiance level and ambient temperature are modified for the verification of the zeta converter's characteristics in real conditions. A comparative study on the output of AFLC with respect to conventional FLC and P and $\mathrm{O}$ methods at different conditions was followed. The simulation for three MPPT methods has been performed using MATLAB/Simulink environment for two cases when solar irradiance is changed and ambient temperature is kept constant and another when ambient temperature is changed and solar irradiance is kept constant.

\subsection{When solar irradiance is changed and ambient temperature is kept constant}

The $200 \mathrm{~W}$ PV system's simulated results, when irradiance level is changed and environment temperature is maintained constant at $25^{\circ} \mathrm{C}$ are clearly represented in Fig. 7. The figure depicts the simulated responses of PV load curves and operating point for 10 second simulation period. From 0.5 to $4 \mathrm{~s}$, irradiance level increase linearly and it stays at $1000 \mathrm{~W} / \mathrm{m}^{2}$ from 4 to $6 \mathrm{~s}$.Also for 6 to $9.5 \mathrm{~s}$ it decreases linearly and finally it is maintained constant at $200 \mathrm{~W} / \mathrm{m}^{2}$ for 9.5 to $10 \mathrm{~s}$. At t $=4 \mathrm{sec}$, the solar irradiance level is reached to $1000 \mathrm{~W} / \mathrm{m}^{2}$ and maintained constant up to $t=6 \mathrm{~s}$. The solar irradiance level is again assumed to be changed from 1000 to $200 \mathrm{~W} / \mathrm{m}^{2}$ from period $\mathrm{t}=6 \mathrm{~s}$ to $\mathrm{t}=9.5 \mathrm{~s}$ and maintained constant up to $t=10$ s. Fig. 7 (b), (c) and (d) depicts the simulated PV power $\left(\mathrm{P}_{\mathrm{PV}}\right)$ voltage $\left(\mathrm{V}_{\mathrm{PV}}\right)$ and current $\left(\mathrm{IPV}_{\mathrm{PV}}\right)$ responses for AFLC, $\mathrm{P}$ and $\mathrm{O}$ and Fuzzy MPPT algorithm. The simulated response reveals the comparison of the response of three MPPT controllers, when irradiance level is changed and ambient temperature is maintained constant. The simulation result of Fig. 7 shows that the power output comparison of proposed AFLC with conventional fuzzy logic controller and $\mathrm{P}$ and $\mathrm{O}$ method at variable irradiance and constant temperature. Fig. 7, clearly shows that poor oscillation nearer to MPP for $\mathrm{P}$ and $\mathrm{O}$ method is higher than the proposed AFLC method. Also the AFLC tracks more power contrast to the classical FLC, and P and O method. Hence AFLC has more power tracking capability compared to FLC, and P and O method at variable solar irradiance.

\subsection{When ambient temperature is changed and solar irradiance is kept constant}

In this case the Behavior of three MPPT algorithm have been tested under changing environment temperature The simulated responses of PV curves and its operating points for changing ambient temperature and fixed insolation level has been depicted by Fig 8. Simulated results of $200 \mathrm{~W}$ PV systems at variable ambient temperature and standard irradiance level $1000 \mathrm{~W} / \mathrm{m}^{2}$ are described by fig. 8 . From Fig. 8 (a), the ambient temperature is maintained $10{ }^{\circ} \mathrm{C}$, until $\mathrm{t}=0.5 \mathrm{~s}$. The environmental temperature is varied as a ramp function and reaches $70^{\circ} \mathrm{C}$ at $\mathrm{t}=4 \mathrm{~s}$ and it maintained constant up to $t=6 \mathrm{~s}$. Again ambient temperature is varied from period $\mathrm{t}=6$ to $9.5 \mathrm{~s}$ and reached $10{ }^{\circ} \mathrm{C}$, then assumed to be constant up to $t=10 \mathrm{~s}$. Fig. 8 (b), (c) and (d) show the simulated PPV, VPV and IPv responses for AFLC, P and O and Fuzzy MPPT algorithm respectively. According to Fig. 8, it is evident that at variable ambient temperature and constant irradiance, the oscillation around MPP is more in case of conventional $\mathrm{P}$ and $\mathrm{O}$ method compared to AFLC. Hence AFLC is best method for optimal power tracking from solar array under changing environmental temperature with fixed sun insolation.


(a)

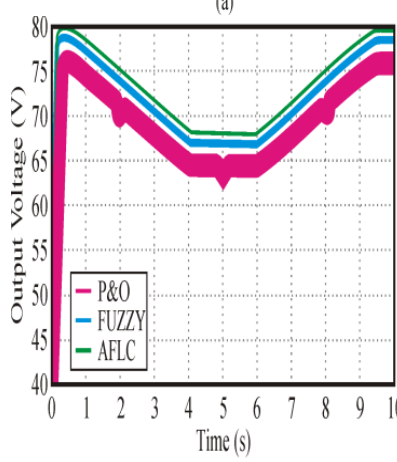

(c)

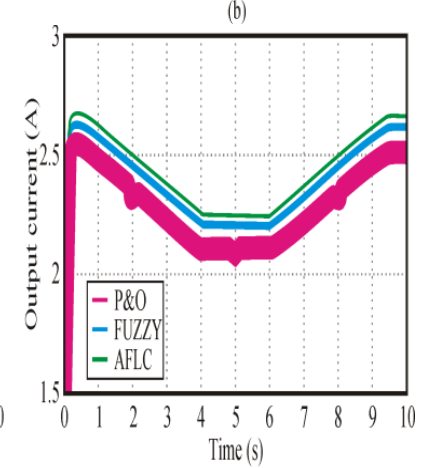

(d)

Fig. 8: Comparison of AFLC, FLC and P\&O Method Under Changing Environmental Temperature with Fixed Sun Insolation (A) Variable Temperature (B) Output Power(C) Output Voltage (D) Output Current.

The compared simulated PV curves and operating point's responses of three MPPT controllers are presented at variable irradiance level and ambient temperature. The simulated results show that the proposed AFLC controller gives small oscillation, smooth power signal, precise response and stable operating point compared to $\mathrm{P}$ and $\mathrm{O}$ and FLC MPPT controllers. Hence, the presented AFLC system has the ability to extract maximum power at different irradiance and ambient temperature efficiently.

\section{Experimental results}

To validate the effectiveness of the system design, an AFLC based MPPT controller for $200 \mathrm{~W}$ rated power PV systems is developed from which experiments are performed. Conventional $\mathrm{P}$ and $\mathrm{O}$ and FLC MPPT prototype circuits are also built which uses the same hardware to validate the tracking accuracy of proposed AFLC MPPT method The structure of the experimentation using dSPACE Platform has been depicted by fig 9 It mainly consists of two solar panel with $100 \mathrm{~W}$ rated power each, zeta buck boost 
converter to regulate load voltage, a dSPACE real time control board, current and voltage sensors and standalone resistive load. For laboratory set up, power quality Fluke 434, oscilloscope (Tektronix), voltmeter and ammeter are employed for measuring the equipments.



Fig. 9: Proposed AFLC Based MPPT Block Diagram For Experimentation.

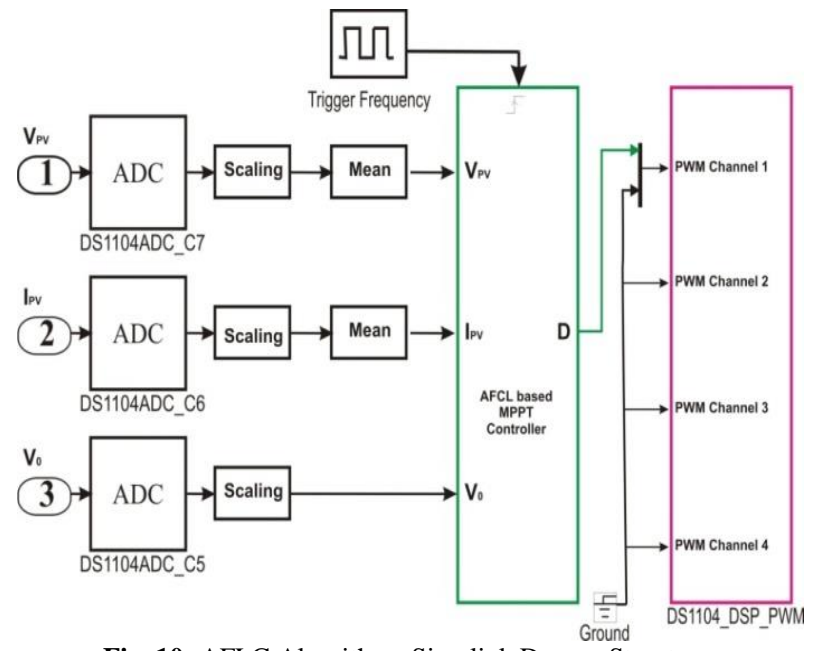

Fig. 10: AFLC Algorithms Simulink Dspace Structure.

Using dSPACE real-time control, the proposed AFLC based MPPT for zeta converter has been implemented. Laboratory set up is enabled by connecting the zeta converter to the PV module. dSPACE DS1104 combined with a digital signal processor, which have been employed for controlling and restoring the output data The PV current and voltage measurement is carried out by the LTS 25-NP current sensor and voltage divider, respectively. The $(\mathrm{VPV})$ and (IPV) act as input to ADC converter and then it employed to AFLC simulink model for PWM pulse generation which is explained by Fig 10. The AFLC simulink model has been experimentally interfaced with dSPACE platform. The experimentation is performed under varying operating conditions. The practical responses show that the MPP's is achieved in each operating condition under relatively small period. Fig. 11 (a) shows that by means of proposed adaptive Fuzzy logic control MPPT, the maximum power is obtained faster and shows negligible fluctuation around maximum power point (MPP) compared to other conventional MPPT methods Have been depicted by Fig. 11 (b) and (c). Hence the AFLC based MPPT always try to maintain the peak power as a new operating position under canging envronmental condition.
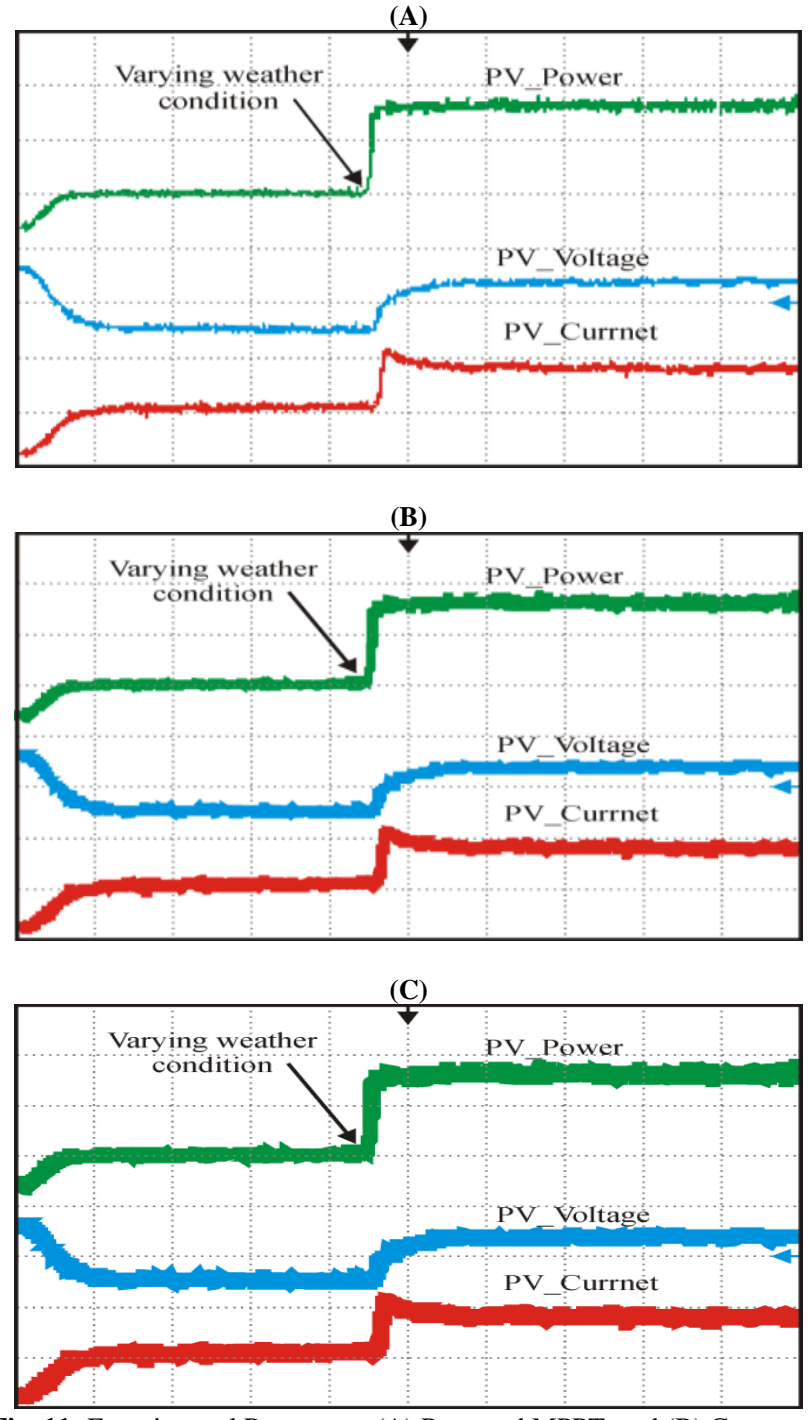

Fig. 11: Experimental Responses: (A) Proposed MPPT, and (B) Conventional FLC MPPT (C) Conventional P and O MPPT.

\section{Conclusion}

This work presents a detailed comparison of an AFLC method with conventional fuzzy logic controller and $\mathrm{P}$ and $\mathrm{O}$ maximum power point tracking controller. A better tracking efficiency was achieved using the AFLC method with respect to the conventional FLC and P and O MPPT. The AFLC based MPPT gives better tracking efficiency under varying irradiance level and ambient temperature. The AFLC based MPPT has been Interfaced with dSPACE platform. The simulated and experimental responses show that the proposed MPPT method gives fast response, precise tracking ability, small oscillation around MPP and better steady and dynamic performances for varying atmospheric conditions. 


\section{References}

[1] A.C. Souza, F.C. Melo, T.L. Oliveira and C.E. Tavares, "Performance Analysis of the Computational Implementation of a Simplified PV Model and MPPT Algorithm," IEEE Latin America transactions, vol. 14, no. 2, pp.792-798, Feb (2016).

[2] M. Alam, J. Jana and H. Saha, "Switched Boost Inverter Applicable for Solar Photovoltaic System Based Micro-Grid," 2nd International Conference on Control, Instrumentation, Energy \& Communication (CIEC), pp. 422-426, (2016)

[3] N. Priyadarshi, V. Kumar, K. Yadav and M. Vardia, "An Experimental Study on Zeta buck-boost converter for Application in PV system" Handbook of distributed generation (Springer) chapter DOI 10.1007/978-3-319-51343-0_13

[4] V.V.S.P. Kumar and B.G. Fernandes, "Minimization of InterModule Leakage Current in Cascaded H-Bridge Multilevel Inverters for Grid Connected Solar PV Applications," pp. 2673-2678, (2016).

[5] A.Maiti, K. Mukherjee and P. Syam, "Design, Modeling and Software Implementation of a Current-Perturbed Maximum Power Point Tracking Control in a DC-DC Boost Converter for GridConnected Solar Photovoltaic Applications," IEEE First International Conference on Control, Measurement and Instrumentation (CMI), pp. 36-41 (2016).

[6] S. Sajadian and R. Ahmadi, "Model Predictive Based Maximum Power Point Tracking for Grid-tied Photovoltaic Applications Using a Z-Source Inverter," IEEE Transactions on Power Electronics (2016).

[7] M.B. Shadmand, M. Mosa, R.S. Balog and H.A. Rub, "Maximum Power Point Tracking of Grid Connected Photovoltaic System Employing Model Predictive Control,” pp. 3067-3074, IEEE (2015).

[8] N. Priyadarshi, A. Anand, A.K. Sharma, F. Azam, V.K. Singh, and R.K. Sinha, "An Experimental Implementation and Testing of GA based Maximum Power Point Tracking for PV System under Varying Ambient Conditions Using dSPACE DS 1104 Controller", International Journal Of Renewable Energy Research, Vol.7, No.1, pp. $255-265,2017$.

[9] M.A. El-Sayed, and S. Leeb, "Fuzzy logic based maximum power point tracking using boost converter for solar photovoltaic system in Kuwait," International Conference on Renewable Energies and Power Quality, Spain, vol. 14, no. 13, April (2015).

[10] A.R. Reisi and M.H. Moradi, "Classification and comparison of maximum power point tracking techniques of photovoltaic system: Review", Renewable and Sustainable Energy Reviews. vol. 19, pp. 433-443, (2013)

[11] M.N. Uddin and R.S. Rebeiro, "Online efficiency optimization of a fuzzy-logic-controller-based IPMSM drive," IEEE Transaction of Industrial Electronics, vol. 47, no. 2, pp. 1043-1050, (2011).

[12] M.A. Hannana, Z.A. Ghania, A. Mohameda and M.N. Uddinc, "Real-Time Testing of a Fuzzy Logic Controller Based GridConnected Photovoltaic Inverter System," pp. 4-8, (2014).

[13] A.E. Khateb, N.A. Rahim, J. Selvaraj and M.A. Uddin, "Fuzzy Logic Controller Based SEPIC Converter for Maximum Power Point Tracking," pp. 99, (2014).

[14] N. Shah and R. Chudamani, "Single-Stage Grid Interactive PV System Using Novel Fuzzy Logic Based MPPT with Active and Reactive Power Control,"7th IEEE Conference on Industrial Electronics and Applications (ICIEA), pp. 1667-1672, (2012). 